\title{
A REGIÃO METROPOLITANA DA GRANDE VITÓRIA E APLICAÇÃO DA LEI DE ACESSO À INFORMAÇÃO: UMA ANÁLISE ACERCA DA TRANSPARÊNCIA ATIVA E PASSIVA
}

METROPOLITAN REGION OF VITORIA AND THE APPLICATION OF THE ACCESS TO INFORMATION LAW: AN ANALYSIS OF ACTIVE AND PASSIVE TRANSPARENCY

\author{
Elda Coelho de Azevedo Bussinguer ${ }^{1}$ \\ Juliana Costa Zanganelli
}

\section{RESUMO}

O presente artigo se propôs a analisar em que medida os sítios eletrônicos das prefeituras localizadas na Região Metropolitana da Grande Vitória (RMGV) estão em conformidade com a Lei 12.527/11 (mais conhecida como Lei de Acesso à Informação), de modo a avaliar e a contribuir para

\footnotetext{
${ }^{1}$ Livre Docente pela Universidade do Rio de Janeiro (UniRio). Pós-doutoranda em Saúde Coletiva pela Universidade Federal do Rio de Janeiro (UFRJ). Doutora em Bioética pela Universidade de Braślia (UnB). Mestre em Direitos e Garantias Fundamentais pela Faculdade de Direito de Vitória (FDV). Mestre em Enfermagem pela Universidade Federal do Rio de Janeiro (UFRJ). Graduada em Direito pela Faculdade de Direito de Vitória (FDV. Graduada em Enfermagem e Obstetrícia pela Universidade Federal do Espírito Santo (UFES). Coordenadora do Programa de Pós Graduação em Direito da Faculdade de Direito de Vitória (FDV). Coordenadora de Pesquisa da Faculdade de Direito de Vitória (FDV). Professora do Programa de PósGraduação em Direito da FDV (Mestrado e Doutorado em Direitos e Garantias Fundamentais). Editora da Revista Direitos e Garantias Fundamentais (QUALIS A 1). Coordenadora do Grupo do BIOGEPE- Grupo de Estudos, Pesquisa e Extensão em Políticas Públicas, Direito à saúde e Bioética. Consultora ad hoc da CAPES/MEC, para a área do Direito. Membro da Rede Brasileira de Pesquisa em Direitos e Garantias Fundamentais. Membro do Conselho científico da Sociedade Brasileira de Bioética. Professora Associada II aposentada da Universidade Federal do Espírito Santo (UFES). Instituição: Faculdade de Direito de Vitoria FDV, Espírito Santo. Brasil. E-mail: elda.cab@gmail.com

2 Doutoranda em Direitos e Garantias Fundamentais pela Faculdade de Direito de Vitória (FDV). Mestre em Direitos e Garantias Fundamentais pela Faculdade de Direito de Vitória (FDV). Bacharela em Direito pela Faculdade de Direito de Vitoria (FDV). Cursou um período da Faculdade de Direito pela Universidad Castilla LaMancha (Cuenca, Espanha) após ingressar por meio de um convênio bilateral estabelecido entre a FDV e a UCLM (Agosto de 2011/Janeiro de 2012). Estudou Direito Internacional Privado pela The Hague Academy of International Law, participando do "Doctoral Networking Sessions". É membro do Grupo de Estudos, Pesquisas e Extensão em Políticas Públicas, Direito à Saúde e Bioética. Publicou, em conjunto com as Doutoras Elda Bussinguer e Lígia Bahia, a obra Organizações Sociais de Saúde e a Lei de Acesso à Informação - Transparência, Economicidade e Eficiência. A referida pesquisa foi fruto de uma análise, inclusive, dos relatórios do Tribunal de Contas do Estado do Espírito Santo para investigar em que medida a atuação de tais organizações está em consonância com a legislação de acesso à informação. A obra ainda discute questões de transparência, eficiência, complementaridade dos serviços públicos de saúde e corrupção, abordando também a Lei Anticorrupção e o Compliance. Instituição: Faculdade de Direito de Vitoria - FDV, Espírito Santo. Brasil. E-mail: jzaganelli.mestrado@gmail.com
} 
com o grau de transparência municipal. Esta pesquisa se trata de natureza exploratória e descritiva, além de conferir uma abordagem quantitativa, ao analisar, por meio de doze quesitos, a transparência nos sítios eletrônicos dos sete municípios localizados na RMGV (Cariacica, Fundão, Vitória, Vila Velha, Viana, Serra e Guarapari). Esta pesquisa se justifica na medida em que o Brasil permanece entre os trinta países do mundo a apresentar os melhores índices de legislação de acesso à informação por meio do ranking elaborado pelo Access Info Europe (AIE) e pelo Centre for Law and Democracy (CLD).

Palavras-chave: Lei de Acesso à Informação; Região Metropolitana da Grande Vitória; Transparência Ativa; Gestão Pública; Direito da Cidade.

\section{ABSTRACT}

The article analysis the city halls website of the Metropolitan Region of Vitoria (RMGV), located at the State of Espirito Santo/Brazil, to verify that commitment with the Access to Information Law $(12.527 / 11)$ to assess and contribute to the degree of transparency. This research is exploratory and descriptive. Besides that is quantitative, because analysis twelve topics to verify if have transparency at the websites of the seven cities around RMGV (Cariacica, Fundão, Vitória, Vila Velha, Viana, Serra e Guarapari). This research justify because Brazil is one of the thirty countries in the world that have the best indexes of access to information, according to the rating founded by Access Info Europe (AIE) and the Centre for Law and Democracy (CLD).

Keywords: Law of Access to Information; Metropolitan Region of Vitoria; Active Transparency.

\section{INTRODUÇÃO}

O acesso à informação sempre foi motivo de discussão no mundo, mas, com a introdução dos meios de comunicação e da garantia de direitos, principalmente, consagrados a partir da Revolução Francesa ocorrida entre os anos de 1789 e 1799, este direito, atualmente, assegurado internacionalmente pela Declaração Universal dos Direitos do Homem em 1948, ainda carece melhor proteção.

Por esse motivo, o presente artigo se propôs a analisar em que medida os sítios eletrônicos 
das prefeituras localizadas na Região Metropolitana da Grande Vitória (RMGV) estão em conformidade com a Lei 12.527/11 (mais conhecida como Lei de Acesso à Informação), de modo a avaliar e a contribuir para com o grau de transparência municipal.

Isso porque, o Global Right to Information (2018), fundado pelo Access Info Europe (AIE) e pelo Centre for Law and Democracy (CLD), elencou o Brasil entre os trinta países a apresentar uma das melhores classificações da legislação de acesso à informação, mediante, principalmente, a análise de sessenta e um critérios.

Tendo em vista sua natureza exploratória e descritiva, será realizada uma pesquisa bibliográfica e de documentos para examinar quantitativamente, por meio de doze quesitos, o grau de transparência nos sítios eletrônicos dos sete municípios localizados na RMGV, quais sejam: Cariacica, Fundão, Vitória, Vila Velha, Viana, Serra e Guarapari.

Portanto, o objetivo deste artigo é verificar a compatibilidade entre a legislação de acesso à informação e sua aplicabilidade prática nos sítios eletrônicos das prefeituras municipais localizadas na RMGV e o cumprimento da Lei 12.527/11.

\section{O ACESSO À INFORMAÇÃO NO BRASIL}

O acesso às informações públicas sempre foi pauta de discussão. Na Antiguidade Clássica, apenas os funcionários oficiais ou quem detinha permissão suficiente poderiam ingressar aos depósitos de arquivos, "e, por isso, a conservação dos arquivos sempre estava vinculada ao exercício do poder ${ }^{3}$, conforme Duchein (1983, p. 2). Já na cidade de Atenas, durante o século IV a.c., a disposição de dados para pesquisas não oficiais contribuiu para estreitar a relação com ideais democráticos. Isso porque, o sujeito que estava sendo processado poderia se utilizar desses documentos para elaborar sua defesa (DUCHEIN, 1983, p. 2).

Entre os séculos XV e XVI, historiadores europeus começaram a pleitear permissão para acessar arquivos com o fim de analisá-los e contribuir criticamente com elaboração de pesquisas (DUCHEIN, 1983, p. 3). Contudo, no decorrer desse impasse entre os que buscavam informações e os detentores das mesmas, diversos documentos se perderam. Alguns foram destruídos e outros recuperados.

\footnotetext{
${ }^{3}$ Original: "en efecto: la conservación de los archivos siempre estuvo vinculada al ejercicio del poder".
} 
Assim, apenas a partir do século XVIII, os arquivos públicos começaram a serem disponibilizados aos pesquisadores, (re) nascendo os valores democráticos (DUCHEIN, 1983, p. 3).

A Suécia, por exemplo, elaborou sua primeira legislação sobre o tema no ano de 1776. A Revolução Francesa, ocorrida entre 1789 e 1799, consoante Duchein (1983, p. 3), consagrou os ideais de "liberdade, igualdade e fraternidade", sendo fundamento para consolidação do acesso à informação com a "Ley de 7 Mesidor, Año II", em 25 de junho de 1794, ao garantir que "os documentos dos arquivos nacionais estão a livre e gratuita disposição de qualquer cidadão que os solicitem"4 (DUCHEIN, 1983, p. 3).

Embora, a Revolução Francesa tenha contribuído para a divulgação de dados públicos a qualquer cidadão que o solicite, no ano de 1956, a França regrediu ao possibilitar a autorização ou a negação deste direito, discricionariamente pela autoridade competente (DUCHEIN, 1983, p. 4). Por isso, mesmo com os avanços no que tange a disponibilização de documentos, ainda eram numerosos os arquivos que continuavam em sigilo por inúmeros motivos.

Em todas as partes se fixaram prazos prolongados para autorizar o conhecimento da documentação: 50, 60 anos em geral ou um pouco mais. Por outro lado, em alguns países, particularmente, pouco liberais (Rússia e Turquia), o acesso aos arquivos públicos seguia vinculado a uma permissão individual ${ }^{5}$ (DUCHEIN, 1983, p. 4).

Segundo Duchein (1983, p. 4), com a Primeira Guerra Mundial, entre os anos de 1914 e 1918, o acesso à informação foi bastante facilitado e, por esse motivo, eram irrisórios os países que não admitiam tal direito aos pesquisadores até a Segunda Guerra Mundial (1939-1945). Costa e Fraiz (1989) evidenciaram que a partir da década de 50, a política de conceder livre acesso aos documentos públicos foi influenciada, principalmente pelo,

[...] desenvolvimento científico e tecnológico, o progresso das pesquisas

\footnotetext{
${ }^{4}$ Original: "los documentos de los archivos nacionales [...] están a la libre, y gratuita, disposición de cualquier ciudadano que así lo solicite".

${ }^{5}$ Original: "En todas partes se fijaron plazos bastante prolongados para autorizar el conocimiento de la documentación: 50, 60 años, por lo general, y aun más. Por otra parte, en ciertos países particularmente poco liberales (la Rusia zarista, la Turquía otomana), el acceso a los archivos públicos seguía sujeto a la concesión de un permiso individual".
} 
históricas, a utilização dos métodos quantitativos em pesquisa, a elaboração do conceito de direito à informação. $O$ aparecimento de diversos meios de reprodução e, finalmente, a informática (COSTA; FRAIZ, 1989, p. 64).

Nesse sentido, no ano de 1948, com vistas a reconhecer direitos inalienáveis, os países membros da Organização das Nações Unidas (ONU) proclamaram a Declaração Universal dos Direitos Humanos que, em seu art. 19, assegurou o acesso à informação.

Artigo 19. Todo ser humano tem direito à liberdade de opinião e expressão; esse direito inclui a liberdade de, sem interferência, ter opiniões e de procurar, receber e transmitir informações e ideias por quaisquer meios e independentemente de fronteiras (grifo nosso).

Esse direito, foi previsto pela Constituição Brasileira de 1988, em seu art. 50, inciso XXXIII, ao dispor que:

Todos têm direito a receber dos órgãos públicos informações de seu interesse particular, ou de interesse coletivo ou geral, que serão prestadas no prazo da lei, sob pena de responsabilidade, ressalvadas aquelas cujo sigilo seja imprescindível à segurança da sociedade e do Estado.

Além disso, este mesmo artigo, em seu inciso LX, aduz que "a lei só poderá restringir a publicidade dos atos processuais quando a defesa da intimidade ou o interesse social o exigirem", ou seja, este trecho ressalta a importância do direito à publicidade, de modo que esta é a regra, sendo a exceção evidenciada a partir do momento em que outros direitos são levados em consideração.

O art. 37, da Constituição Federal reafirma este direito-dever ao mencionar que:

Art. 37. A administração pública direta e indireta de qualquer dos Poderes da União, dos Estados, do Distrito Federal e dos Municípios obedecerá aos princípios de legalidade, impessoalidade, moralidade, publicidade e eficiência.

A partir dessa perspectiva, em 2000, foi promulgada a Lei de Responsabilidade Fiscal, com o objetivo de conferir uma gestão fiscal planejada e transparente para prevenir riscos e desvios que desequilibram as contas públicas.

Em 2003, foi criada a Controladoria-Geral da União (BRASIL, 2018d), órgão responsável pela defesa da transparência e combate à corrupção no Brasil. Consequentemente, surgiram os chamados "Portais da Transparência" (BRASIL, 2018e) no ano seguinte como forma de disponibilizar as informações públicas online para todos os cidadãos. Esses portais teriam a finalidade de informar acerca de assuntos relacionados à gestão pública. 
Mesmo assim, a interação com governo não estava sendo suficiente para o exercício do controle social e, nesse sentido, foi promulgada a Lei 12.527/11, mais conhecida como Lei de Acesso à Informação. Essa Lei dispõe acerca dos procedimentos a serem utilizados pelos entes federativos para viabilizar o acesso às informações, tendo em vista os artigos 5o, 37 e 216 da Magna Carta.

Em um ranking elaborado pelo Global Right to Information (2018), o Brasil ocupa o vigésimo segundo lugar em legislação de acesso à informação, após a promulgação da Lei 12.527/11. Fundado pelo Access Info Europe (AIE) e pelo Centre for Law and Democracy, este ranking analisa as legislações de acesso à informação dos países por meio de sessenta e um indicadores para proporcionalizar uma avaliação precisa das lacunas existentes no arcabouço legal dos países. Essa ferramenta oportuniza a identificação, assim, das áreas que devem ser otimizadas.

O acesso às informações públicas é componente fundamental para o desenvolvimento, uma vez que somente assim é possível auferir o cumprimento dos compromissos assumidos pelo governo e, cobrar, exercendo e contribuindo para com a participação popular, o controle social e a cidadania.

Algumas medidas entre os anos de 1994 e 2005 foram efetuadas para dispor acerca da consulta pública de documentos sigilosos. Exemplo disso, são os Decretos 2.134/97, 2.910/98, 4.553/02, 5.031/04, como também a Lei 11.111/05, que regulamentou o inciso XXXIII do art. 5ㅇ, da Constituição Federal sobre o direito de acesso à informação pública.

Em 2008, a Organização das Nações Unidas para Educação, Ciência e Cultura

- UNESCO, apresentou que desde o ano de 1990 os países passaram a regulamentar o direito de acesso à informação, bem como o reconheceram como um direito fundamental (BRASIL, 2018b, p. 14). Nesse sentido, no ano de 2009, foi encaminhado à Câmara dos Deputados pelo Poder Executivo, o Projeto de Lei 5.228 com a finalidade de regular o inciso XXXIII do art. 5으, o inciso II do § 3o do art. 37 e o § 2o do art. 216 da Magna Carta. Conforme a Exposição de Motivos do projeto, foi ressaltado que a matéria precisava ser regulamentada de forma "unitária e sistemática", por ser “indispensável ao exercício da cidadania” (BRASIL, 2018b, p. 14).

Como proposta, a restrição ao acesso, tendo em vista a Exposição de Motivos, "somente será permitida em caso de informações pessoais ou imprescindíveis à segurança da sociedade e do Estado, 
caso em que a restrição será imposta por meio de classificação de informação como sigilosa". Ademais, o anteprojeto visa a redução dos prazos de restrição, sendo os casos de prorrogação possíveis apenas para as informações classificadas como ultrassecretas, demonstrando "avanços nos critérios de classificação e reclassificação" (BRASIL, 2018b, p. 15).

Cabe dispor ainda que a Exposição de Motivos visa o tratamento do acesso à informação como direito fundamental com a função de consolidar a democracia participativa, razão pela qual, conclui que:

O acesso à informação pública, portanto, como expressão de transparência pública, deve não apenas compreender a acessibilidade de informações, mas, também, a garantia de que o ambiente onde são geradas tais informações não seja contaminado por ações de corrupção, abusos e desmandos (BRASIL, 2018b, p. 17).

No ano seguinte, este projeto que evidenciava como dever do Estado a garantia ao acesso à informação mediante linguagem de fácil compreensão, foi enviado ao Senado Federal e chamado de Projeto de Lei $41 / 10$.

Procedimentos a serem observados pelos órgãos públicos para garantir o acesso à informação previsto na Constituição Federal - diretrizes; gestão, acesso e divulgação da informação; pedido de acesso à informação e recurso contra seu indeferimento; restrições de acesso à informação: classificação da informação quanto ao grau e prazos de sigilo, proteção e controle de informações sigilosas, procedimentos de classificação de informações sigilosas, tratamento das informaç̧ões pessoais; tipificação de condutas ilícitas geradoras de responsabilidade dos agentes públicos; criação da Comissão Mista de Reavaliação de Informações; instituição do Núcleo de Segurança e Credenciamento no âmbito do Gabinete Institucional da Presidência da República; prazo de 180 dias para o Poder Executivo regulamentar o disposto na lei (BRASIL, 2018i).

Cabe considerar que entre 2001 e 2018, trezentos e dezessete Projetos de Lei foram apresentados à Câmara dos Deputados acerca do direito ao acesso à informação pública.

No mês de novembro de 2011, o referido projeto foi convertido na Lei 12.527 , mais conhecida como a Lei de Acesso à Informação, a qual dispôs acerca dos procedimentos a serem observados pelos entes federativos para a garantia deste direito que, também deve recair às entidades privadas sem fins lucrativos que recebam recursos públicos diretamente do orçamento ou mediante subvenções sociais (art. 2ํ).

Dentre os procedimentos elencados pelo art. 3ำ da referida Lei, estão: i) a observância da 
publicidade como preceito geral; ii) a divulgação das informações de interesse público; iii) a utilização dos meios de comunicação; iv) o desenvolvimento da transparência pública e; v) o desenvolvimento do controle social. Nesse sentido, segundo o art. 5ํ, passa a ser "dever do Estado garantir o direito de acesso à informação, que será franqueada, mediante procedimentos objetivos e ágeis, de forma transparente, clara e em linguagem de fácil compreensão". Como dever do Estado, a transparência das informações públicas deve ser disponibilizada tanto em sua forma ativa, quanto passiva.

\begin{abstract}
Nós chamamos de transparência ativa a divulgação espontânea, proativa, de informações, pelo Estado, pelos meios disponíveis. Claro que hoje, na era da internet, o meio eletrônico, a própria internet foi eleita o canal prioritário pelo legislador. [...] São informações referentes à estrutura organizacional, funcionamento dos órgãos, competências, o quem é quem, o horário de funcionamento, despesas, repasses, convênios, licitações e contratos e perguntas mais frequentes. A lei é expressa em prever que nós, Estado, deveremos trabalhar para identificar aquilo que nos é mais demandado pela sociedade e nos anteciparmos para colocarmos isso proativamente na internet, a fim de facilitar que o cidadão encontre essa informação. Já a transparência passiva é a obrigação do Estado de atender pontualmente os pedidos de acesso à informação que nos serão apresentados (VIEIRA, 2018, p. 12-14).
\end{abstract}

Enquanto na transparência ativa a disposição de dados é espontânea nos meios de comunicação, como na internet, de modo que antes do cidadão requisitar quaisquer informações sobre o uso do dinheiro público, poderá verificá-las online. O art. 8o da Lei 12.527/11 realça que este dever de órgãos e entidades deve ser realizado: "independentemente de requerimentos" e em "local de fácil acesso". Além disso, os sítios eletrônicos devem obedecer requisitos como: i) conter ferramentas de pesquisa de fácil compreensão; ii) possibilitar a gravação de relatórios em diferentes formatos eletrônicos; iii) possibilitar acesso automatizado por sistemas externos em formatos abertos; iv) divulgar os detalhes para a estruturação da informação; v) garantiar a autenticidade das informações; vi) indicar local e instruções para eventual comunicação via telefone ou presencial; vii) manter atualizadas as informações e; viii) adotar medidas necessárias para garantir o acesso dos conteúdos por pessoas com deficiência.

Já na transparência passiva, não há o encontro das informações disponíveis nos meios eletrônicos e, por esse motivo, o cidadão as pleiteia por meio de solicitações que, mediante a Lei 12.527/11, devem ser respondidas em até vinte dias corridos. Para tanto, deve ser assegurada a criação do serviço de informação ao cidadão (SIC) para atender e orientar o público, de modo online e presencial. Este serviço online deve propiciar ao cidadão o acompanhamento das suas solicitações, 
como também a viabilidade de oferecer recursos ante as eventuais respostas (art. 15).

Consoante Sarlet e Molinaro (2016, p. 19-20), o SIC foi desenvolvido para facilitar o controle social, sendo assim, uma "porta de entrada única" dos registros de pedidos de informação. Ao operacionalizar este direito, concentrando as informações nos sítios eletrônicos que, quando não localizadas, possam ser solicitadas e adquiridas, posteriormente, tanto a transparência ativa, quanto a passiva, são garantidas. Atrelado a isso, Polízio Júnior $(2015$, p. 62) ressalta que:

É por meio da informação sobre a atuação do Estado e sobre o uso do dinheiro público, ou melhor, sobre a Administração Pública em sentido amplo, que a República se tornará verdadeiramente democrática e de direito. Cidadania pressupõe conhecimento e, conhecimento exige informação (POLÍZIO JÚNIOR, 2015, p. 62).

Embora os avanços normativos tenham sido significativos ao longo dos anos no Brasil, a luta pela garantia ao direito à informação ainda é um desafio atual.

\section{O ACESSO À INFORMAÇÃO NA REGIÃO METROPOLITANA DA GRANDE VITÓRIA}

Assegurado do ponto de vista internacional, nacional e infraconstitucional, principalmente, com a Lei 12.527 promulgada no ano de 2011, o acesso à informação é considerado um direito fundamental que deve ser respeito e garantido para a promoção do exercício da cidadania. Sob essa perspectiva, foi analisado neste item o grau de transparência pública nas cidades localizadas na RMGV.

Foi durante o governo de Jerônimo Monteiro, no início do século XX (1908-1912), que o projeto para a urbanização do Estado do Espírito Santo começou a ser desenvolvido. Com a finalidade de industrializar e promover a expansão da capital do Estado, foram implementadas medidas como:

a. Aparelhamento do Porto de Vitória objetivando a exportação de café, nesse momento já o principal produto da economia capixaba;

b. Instalação do bonde elétrico, com a ampliação da linha ligando Santo Antônio até a Praia do Suá e implantação da linha circular ligando a cidade alta à baixa;

c. Renovação do núcleo antigo da cidade, através da retificação e ampliação de 
vias, dos serviços de água, drenagem e limpeza pública;

d. Implantação do projeto "Novo Arrabalde", de Saturnino de Brito, ampliando em cinco vezes a área da cidade;

e. Construção da ponte Florentino Avidos, possibilitando a ligação de Vitória à Ilha do Príncipe e ao Continente (MATTOS, 2013, p. 94).

Com o movimento migratório e o processo de urbanização acelerados, bairros periféricos surgiram e intensificaram a desigualdade social na região (MATTOS, 2013, p. 109). No ano de 1967, foi incorporada à Constituição da época, a Emenda Constitucional n. 848 que viabilizava a criação de Regiões Metropolitanas. Mas, apenas no ano de 1995 foi instituída a RMGV por meio da Lei Complementar Estadual n. 58 (MATTOS, 2013, p. 117).

Esta região metropolitana foi inicialmente formada pelos municípios de Cariacica, Serra, Viana, Vila Velha e Vitória, "com vistas à organização, ao planejamento e à execução de funções públicas de interesse comum, no âmbito metropolitano" (ESPÍRITO SANTO, 2018). Após alterações no ano de 1999 (Lei Complementar n. 159) e no ano de 2001 (Lei Complementar n. 318), atualmente, a região compreende também os municípios de Guarapari e Fundão. Cabe ressaltar que, conforme o Instituto Brasileiro de Geografia e Estatística Geral (IBGE), as sete cidades perfazem uma população de 1.960.213 habitantes no ano de 2017 (BRASIL - Ibge, 2018).

Em relatório produzido pelo Instituto de Pesquisa Econômica Aplicada (IPEA) para analisar a evolução nos índices da RMGV, como a taxa de crescimento, o índice de desenvolvimento humano municipal (IDHM) e o produto interno bruto (PIB), verificou-se que:

i. " [...] a taxa de crescimento da população da RM da Grande Vitória, entre 2000 e 2010, foi de 1,61\% ao ano" (BRASIL, 2018g, p. 112);

ii. " [...] em 2000, a RM da Grande Vitória apresentava IDHM igual a 0,678, situando-se na faixa de Médio Desenvolvimento Humano. Já em 2010, a RM apresentava IDHM de 0,772, passando para a faixa de Alto Desenvolvimento Humano" (BRASIL, 2018g, p. 112);

iii. Enquanto em 2000, o PIB era R\$ 13,89 bilhões (64,5\% do total estadual), em 2010 , passou a ser $\mathrm{R} \$ 51,86$ bilhões (63,2\% do total estadual) (BRASIL, 2018g, p. 110-11).

Nesse sentido, além da facilidade de localização, a RMGV compreende aspectos e índices expressivos e, por esse motivo, o recorte desse estudo foi realizado nesta região. 
A difusão dos meios de comunicação e a garantia da criação de mecanismos que possibilitassem a transparência ativa e passiva, conferiu ao avanço tecnológico o título de "mais letal instrumento contra a corrupção do Poder Público e o mau uso dos recursos do erário" (POLízIO JÚNIOR, 2015, p. 57). Isso porque, com o fito de garantir o exercício da cidadania por meio do controle social e da participação popular por meio das informações disponibilizadas, este cenário viabiliza o cumprimento de promessas eleitorais e o comprometimento com a gestão pública.

No sentido de proporcionar maior transparência e clareza dos dados de interesse público, a Lei de Responsabilidade Fiscal, em seus arts. 48 e 48-A ressalta que:

Art. 48. São instrumentos de transparência da gestão fiscal, aos quais será dada ampla divulgação, inclusive em meios eletrônicos de acesso público: os planos, orçamentos e leis de diretrizes orçamentárias; as prestações de contas e o respectivo parecer prévio; o Relatório Resumido da Execução Orçamentária e o Relatório de Gestão Fiscal; e as versões simplificadas desses documentos. (grifo nosso).

Art. 48-A. Para os fins a que se refere o inciso II do parágrafo único do art. 48, os entes da Federação disponibilizarão a qualquer pessoa física ou jurídica o acesso a informações:

I - quanto à despesa: todos os atos praticados pelas unidades gestoras no decorrer da execução da despesa, no momento de sua realização, com a disponibilização mínima dos dados referentes ao número do correspondente processo, ao bem fornecido ou ao serviço prestado, à pessoa física ou jurídica beneficiária do pagamento e, quando for o caso, ao procedimento licitatório realizado;

II - quanto à receita: o lançamento e o recebimento de toda a receita das unidades gestoras, inclusive referente a recursos extraordinários (grifo nosso). 
Mediante a Lei de Responsabilidade Fiscal, a ampla divulgação de dados inclui, dentre outros, os planos orçamentários, as diretrizes, prestações de contas, relatórios, a realização de audiências públicas, a adoção de um sistema integrado de controle, com o intuito de incentivar a participação popular e o pleno conhecimento dos gastos públicos.

A Lei de Acesso à Informação, por sua vez, dispõe acerca dos procedimentos a serem observados pelos entes federativos, como também para aqueles que se subordinam a referida Lei, como as autarquias, fundações, empresas públicas, sociedades de economia mista, dentre outras entidades que se utilizam de recursos públicos para desempenhar suas atividades. Por esse motivo, a Lei elenca em seu art. 70 os direitos dos cidadãos em obter, dentre outros:

I - orientação sobre os procedimentos para a consecução de acesso, bem como sobre o local onde poderá ser encontrada ou obtida a informação almejada;

II - informação contida em registros ou documentos, produzidos ou acumulados por seus órgãos ou entidades, recolhidos ou não a arquivos públicos;

III - informação produzida ou custodiada por pessoa física ou entidade privada decorrente de qualquer vínculo com seus órgãos ou entidades, mesmo que esse vínculo já tenha cessado;

IV - informação primária, íntegra, autêntica e atualizada;

V - informação sobre atividades exercidas pelos órgãos e entidades, inclusive as relativas à sua política, organização e serviços;

VI - informação pertinente à administração do patrimônio público, utilização de recursos públicos, licitação, contratos administrativos [...].

Contudo, apesar da legislação em vigor acerca da garantia do direito à informação no Brasil e, mesmo com a classificação do país em vigésimo segundo lugar no ranking elaborado pelo Global Right to Information (2018), ainda é possível perceber que a aplicabilidade prática se destoa. Ao realizar uma auditoria nos municípios capixabas, o Tribunal de Contas do Estado do Espírito Santo constatou que alguns artigos da Lei de Acesso à Informação são inteiramente descumpridos. 


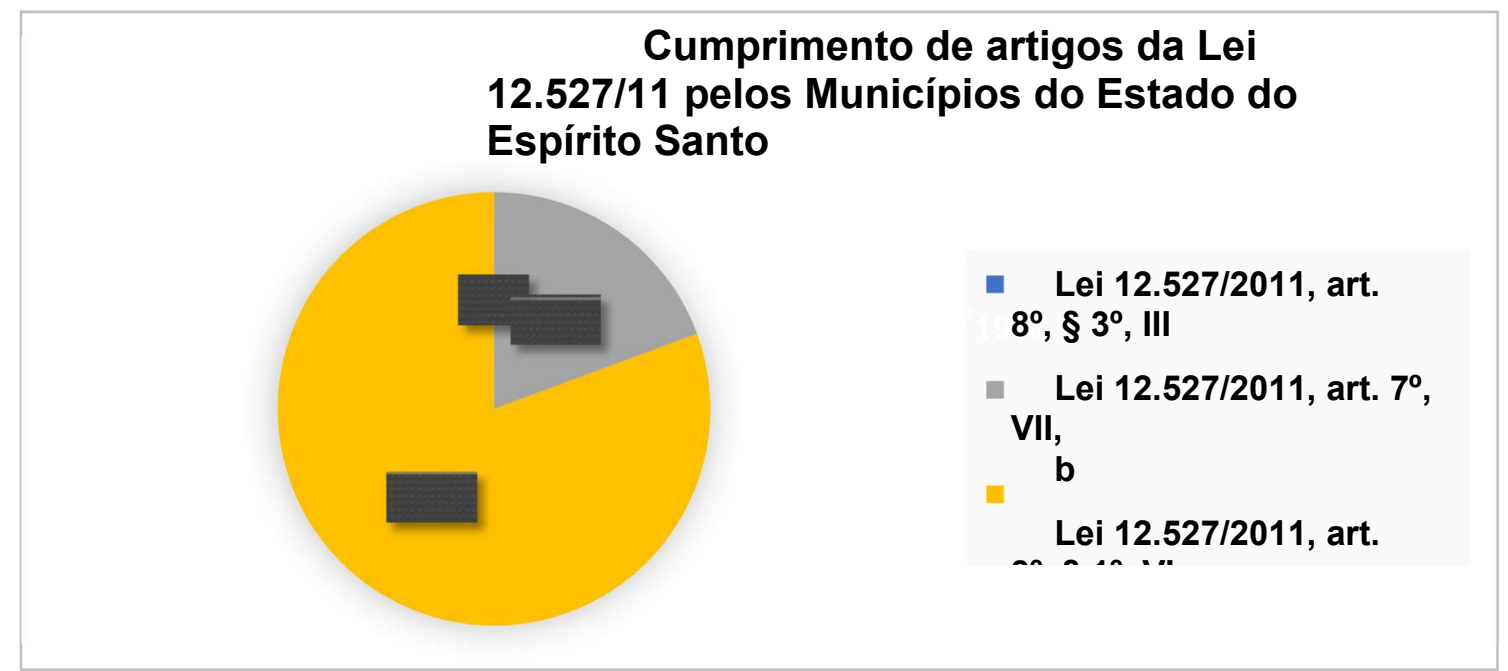

Fonte: Elaboração Própria, tendo como base o Relatório de Auditoria 16/2015 elaborado pelo TCE-ES e proveniente do processo 2918/2015, p.166.

Pela Gráfico 1, nota-se que o inciso III do §3ㅇ do art. 8o da Lei 12.527/2011 foi completamente desatendido na auditoria realizada pelo Tribunal de Contas do Estado do Espírito Santo. O referido artigo versa acerca da transparência ativa, ao promover o dever dos órgãos e das entidades públicas em divulgar, de forma clara e independente de solicitações pelo SIC, informações de interesse público. Observe:

Art. - $8^{\circ}$ É dever dos órgãos e entidades públicas promover, independentemente de requerimentos, a divulgação em local de fácil acesso, no âmbito de suas competências, de informações de interesse coletivo ou geral por eles produzidas ou custodiadas.

$\S-1^{\circ} \mathrm{Na}$ divulgação das informações a que se refere o caput, deverão constar, no mínimo:

$\mathrm{VI}$ - respostas a perguntas mais frequentes da sociedade. [...]

$\S 3^{\circ-}$ Os sítios de que trata o $\S 2^{\circ}$ deverão, na forma de regulamento, atender, entre outros, aos seguintes requisitos:

III - possibilitar o acesso automatizado por sistemas externos em formatos abertos, estruturados e legíveis por máquina.

Art. $\quad-7^{\circ} \mathrm{O}$ acesso à informação de que trata esta Lei compreende, entre outros, os direitos de obter: 
VII - informação relativa:

b) ao resultado de inspeções, auditorias, prestações e tomadas de contas realizadas pelos órgãos de controle interno e externo, incluindo prestações de contas relativas a exercícios anteriores (grifo nosso).

Além disso, mesmo com todo o arcabouço normativo que trata do acesso à informação no Brasil, também foi verificado pela auditoria que apenas $42,8 \%$ do Poder Executivo cumpre com a legislação de acesso à informação.

Gráfico 2 - Cumprimento da Legislação de Acesso à Informação pelo Poder Executivo dos Municípios Brasileiros

\section{Poder Executivo - Cumprimento da Legislação de}

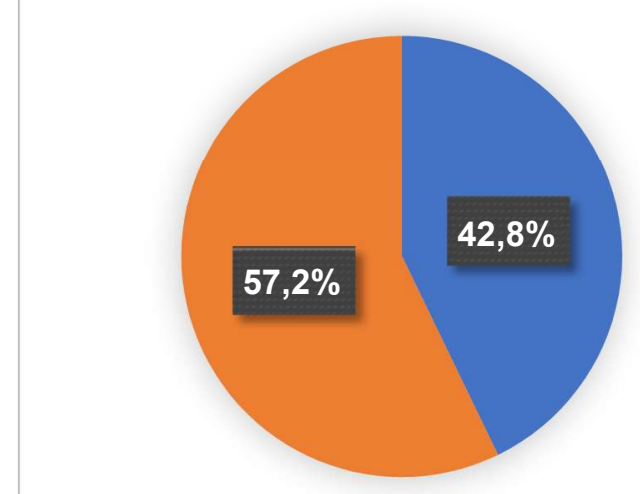

- Cumpre a Legislação

Fonte: Elaboração Própria, tendo como base o Relatório de Auditoria 16/2015 elaborado pelo TCE-ES e proveniente do processo 2918/2015, p. 142.

Pelo Gráfico 2, nota-se que o percentual de descumprimento da legislação é ainda maior, perfazendo um total de 57,2\%. Contudo, ao realizar a análise para verificação dos dados disponibilizados, o Tribunal de Contas do Estado do Espírito Santo concluiu que apenas 39,19\% dispõe acerca do conteúdo das informações. Observe: 
Gráfico 3 - Disponibilização do conteúdo das informações pelo Poder Executivo dos Municípios Brasileiros

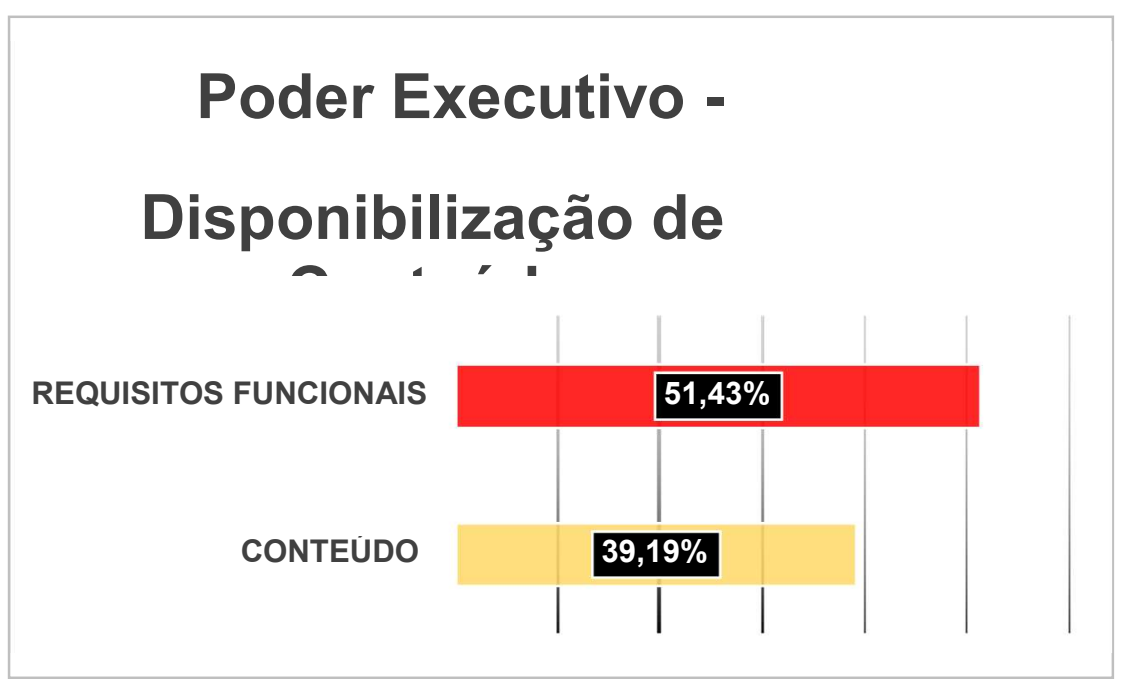

Fonte: Elaboração Própria, tendo como base o Relatório de Auditoria 16/2015 elaborado pelo TCE-ES e proveniente do processo 2918/2015, 143.

É possível verificar que grande parte das informações disponibilizadas pelo Poder Executivo dos municípios capixabas são relativos a requisitos funcionais, o que intensifica ainda mais o desacordo com a legislação de acesso à informação. Mesmo porque, o mero depósito de dados não permite o controle social. No que diz respeito aos municípios localizados na RMGV, foi constatado pela auditoria acima mencionada que o cumprimento da legislação de acesso à informação varia entre $20 \%$ e 60\%, conforme é apresentado no Gráfico 4. 


\section{Índice de Cumprimento da \\ Legislação de Acesso à Informação pelos Municípios RMGV}

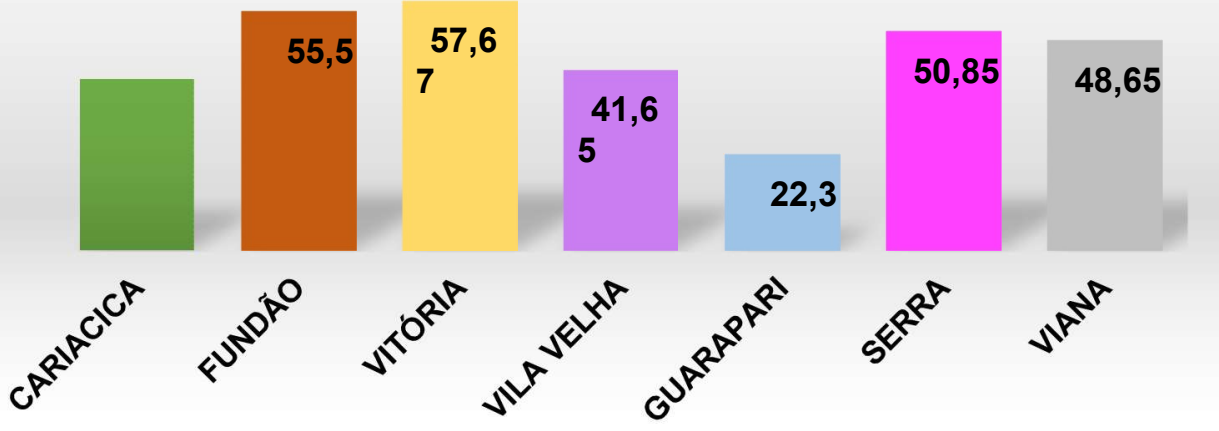

Fonte: Elaboração Própria, tendo como base o Relatório de Auditoria 16/2015 elaborado pelo TCE-ES e proveniente do processo 2918/2015, 147-150.

Logo, verifica-se que em Guarapari há descumprimento da legislação de acesso a informação em quase $80 \%$. Já na cidade de Cariacica, apenas 39,73\% cumpre com a mesma. O município de Vitória, Fundão e Serra apresentam índices pouco melhores, mas que não ultrapassam os $60 \%$ em transparência pública. Esses indicativos contrariam, por exemplo, o panorama apresentado pela CGU por meio da "Escala Brasil Transparente" (BRASIL, 2018f), que, por meio de uma metodologia específica, avalia os municípios brasileiros, concedendo notas de 0 a 10 que evidenciam um grau de transparência. Isso porque, por essa avaliação nota-se que:

i. Cariacica e Vitória apresentam nota 10 em transparência pública.

ii. Serra e Viana possuem nota 9,16. 

iii. Vila Velha apresenta nota 8,75.
iv. Fundão apresenta nota 7,77 .
v. Guarapari não foi avaliado 6 .

Cabe ressaltar que embora na terceira avaliação (12/07/2016 a 28/11/2016) o município de Vitória tenha apresentado nota 10 em transparência pública, ao observar os critérios utilizados pela "Escala Brasil Transparente", nota-se descumprimento em três critérios na primeira avaliação (01/04/2015 a 24/04/2015).

Portanto, por meio do relatório de auditoria 16/2015, o Tribunal de Contas do Estado do Espírito Santo, observou que a legislação de acesso à informação ainda é amplamente descumprida e, concluiu, afirmando que um dos grandes empecilhos para o seu atendimento é "[...] a vontade política, ou seja, a disposição dos gestores públicos em disponibilizar maior quantidade e qualidade de informações aos cidadãos é um dos fatores que exerce maior influência no nível de transparência do ente público" (ESPÍRITO SANTO, 2015, p. 200).

\section{APLICAÇÃO DA LEI DE ACESSO À INFORMAÇÃO NOS MUNICÍPIOS LOCALIZADOS NA REGIÃO METROPOLITANA DA GRANDE VITÓRIA: A TRANSPARÊNCIA PÚBLICA NA CONTRATAÇÃO DE ORGANIZAÇÕES SOCIAIS DE SAÚDE}

O setor saúde movimentou no ano de 2017, conforme o Projeto de Lei Orçamentária Anual, cerca de R\$110,2 bilhões de reais (BRASIL, 2018h). No que diz respeito as OSS, a transferência de recursos públicos se revela expressiva ao analisar os contratos de gestão e os termos aditivos. Isso se verifica ao observar que determinadas organizações sociais, como a Associação Paulista para o Desenvolvimento da Medicina (SPDM) e a Associação Congregação de Santa Catarina (ACSC) estão elencadas no ranking elaborado pela revista "Valor Econômico" como uma das maiores empresas brasileiras, movimentando milhões de reais. Em 2014, enquanto a SPDM (VALOR, 2018b) foi classificada em 1670 lugar, a ACSC (VALOR, 2018a) em 2015 apareceu em 280ㅇ lugar.

Esse quadro, retrata a importância da transparência quanto a destinação dos recursos públicos para propiciar o controle social e a análise dos parâmetros de eficiência e qualidade na prestação dos serviços de saúde. Pressupostos que foram essenciais à época da Reforma do Estado.

\footnotetext{
${ }^{6}$ No dia 11 de julho de 2018 foi enviado por meio do SIC da Controladoria Geral da União um pedido de explicação quanto a não avaliação do município de Guarapari, contudo, até o momento, não se obteve respostas.
} 
Na década de 60, o Brasil enfrentou crises econômicas que suscitaram debates em torno da eficiência na gestão pública (BRESSER-PEREIRA, 2018a, p. 13), consequentemente, as políticas sociais foram afastadas para ceder espaço a chamada "Globalização Corporativa Neoliberal" (SIQUEIRA et. al., 2003, p. 849). A intenção dessa política era promover um arrocho nas contas públicas e permitir maiores privatizações.

Com a promulgação da Constituição Federal de 1988, o país centralizou novamente seus esforços nos direitos sociais, no entanto, mesmo assim, com as reiteradas crises na Administração Pública, Bresser-Pereira foi nomeado, em 1995, pelo Presidente Fernando Henrique Cardoso para o cargo de ministro da Administração Federal e da Reforma do Estado para promover a Reforma Gerencial do Estado e garantir maior flexibilização da gestão pública. No mesmo ano, o Plano Diretor de Reforma do Aparelho do Estado (PDRAE) foi elaborado e, em 1997, as Organizações Sociais de Saúde (OSS) foram criadas pela Lei 9.637/98 (BRESSER-PEREIRA, 2018a, p. 22-23).

Nesse sentido, era proposta uma "Administração Pública inovadora, aberta à experimentação de novos formatos organizacionais e institucionais, mais ágeis e flexíveis" (BRESSERPEREIRA, 2018b, p. 3). A Reforma Gerencial, portanto, tinha como estratégia reduzir os custos e garantir maior eficiência na prestação dos serviços públicos. Por esse motivo, as OSS foram criadas, já que a Administração Direta não proporcionava à população brasileira um "serviço adequado" de saúde.

No entanto, a Magna Carta ressaltou o caráter complementar dessa transferência da execução dos serviços de saúde (art. 199, §1ํ, CF), cenário que, atualmente, se revela invertido, uma vez que essa exceção se tornou uma regra. Inclusive, pelo índice de crescimento das OSS no país foi proposta a Ação Direta de Inconstitucionalidade no 1.923/05 (BRASIL, 2018a) para declarar inconstitucional a Lei 9.637/98. Contudo, ao ser julgada constitucional em 2015, permitiu a celebração dos contratos de gestão sem procedimento licitatório.

Por meio da auditoria realizada pelo Tribunal de Contas do Estado do Espírito Santo ao analisar o cumprimento da legislação de acesso à informação pelos municípios capixabas, verificouse que o item relativo a disponibilização da íntegra dos contratos administrativos apresentava um percentual de 3,5\%, demonstrando um grau baixo de atendimento (ESPÍRITO SANTO, 2015, p. 163). 
Conforme a Lei $12.527 / 11$, não cabe apenas aos entes federativos dispor acerca das informações de interesse público à população, mas também às entidades privadas que recebem recursos públicos por meio de contrato de gestão, ou seja, as OSS também devem atender e se comprometer com a legislação de acesso à informação (arts. 1ํe e 2ㅇ).

Desse modo, tanto o Poder Público, quanto as OSS devem disponibilizar todos os documentos acerca da contratação, mesmo porque além do dever de garantir o direito fundamental de acesso à informação, os repasses de verba pública à essas organizações são volumosos e precisam ser objeto também de controle social.

Para verificar a aplicabilidade da Lei 12.527/11 foram elaborados oito critérios com base na referida lei, conforme expõe a Tabela 1.

Tabela 1 - Critérios gerais de verificação da transparência ativa nos sítios eletrônicos com base na Lei $12.527 / 11$

1. Está disponível uma "aba" de nome Lei de Acesso à Informação?

2. As disposições acerca da Lei de Acesso à Informação são facilmente encontradas?

Por exemplo, por meio de um clique?

3. Há uma "aba" específica acerca do tema "transparência"?

4. É possível por meio do site acesso ao Portal da Transparência?

5. O ícone do Serviço de Informação ao Cidadão (SIC) é facilmente visualizado? 
6. Há SIC eletrônico?

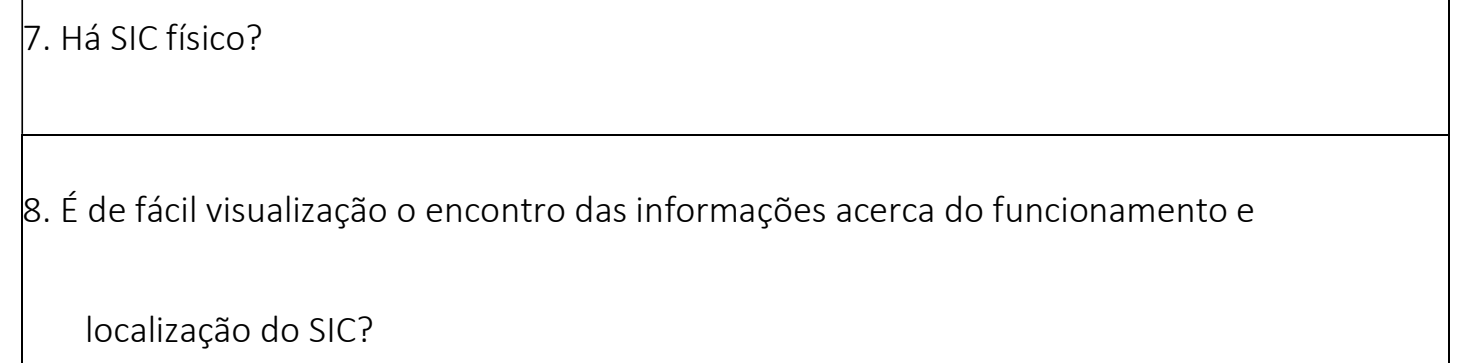

Como resultado dessa análise, se observou que, dos sete municípios estudados, apenas Serra e Fundão disponibilizam uma "aba" com o nome "Lei de Acesso à Informação" ou faz referência a legislação em vigor que seja facilmente encontrada pelo cidadão. Tendo em vista os critérios quanto ao SIC, todos os municípios apresentaram o ícone e as informações acerca do funcionamento de modo compatível com a Lei 12.527/11, exceto Guarapari, que dificultou tais informações e sequer apresentou a existência de SIC físico.

Nota-se que os sítios eletrônicos das prefeituras municipais localizadas na RMGV não atendem a legislação de acesso à informação em sua íntegra, de modo que pode ser expresso da seguinte maneira no Gráfico 5 abaixo.

Gráfico 5 - Região Metropolitana da Grande Vitória e a Lei de Acesso à Informação. 


\section{Região Metropolitana da Grande Vitória e Lei de Acesso}

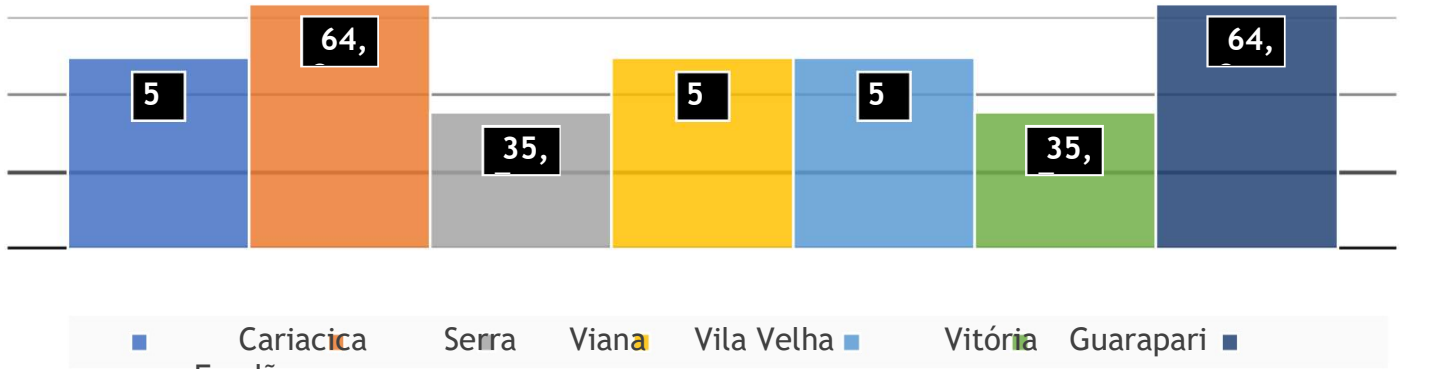

Fonte: Elaboração própria com base na Lei 12.527/11.

Além das informações gerais acima, foi preciso elaborar critérios quanto a disposição de dados no que tange às OSS, conforme a Tabela 2 abaixo.

Tabela 2 - Critérios de verificação da contratação de OSS com base na Lei 12.527/11.

1. Está disponível uma "aba" de nome "Organizações Sociais de Saúde"?

2. Está disponível a listagem das Organizações Sociais de Saúde contratadas pelo Município?

3. É possível localizar as OSS contratadas pelo Portal da Transparência Municipal?

4. As informações públicas acerca das OSS são encontradas de forma ágil, clara e em 


\begin{tabular}{|l|}
\hline linguagem de fácil compreensão? \\
\hline 5. É possível encontrar todos os contratos de gestão (na íntegra) celebrados entre o \\
Município e uma Organizações Sociais de Saúde? \\
\hline
\end{tabular}

Fonte: Elaboração Própria com base na Lei 12.527/11.

Ao proceder na análise acima, constatou-se que nenhum dos sete municípios localizados na RMGV informaram acerca da contratação de organizações sociais. E, por esse motivo, com vistas a verificar o comprometimento dos municípios quanto a transparência passiva, foram enviadas solicitações por meio do SIC para entender o procedimento de contratação via OSS.

Para aferir o grau de atendimento quanto a transparência passiva, tal como posta pela Lei 12.527/11, foram elencados os seguintes parâmetros.

Tabela 2 - Critérios de verificação da contratação de OSS com base na Lei 12.527/11.

1. Os pedidos foram respondidos dentro do prazo de vinte dias conferidos pela Lei de Acesso à Informação?

2. A resposta foi em conformidade com a solicitação?

3. Em caso de respostas às solicitações pelo SIC eletrônico, é possível 


\begin{tabular}{|c|}
\hline recorrer das respostas? \\
\hline 4. Os pedidos podem ser acompanhados por meio do E-SIC? \\
\hline
\end{tabular}

Fonte: Elaboração Própria com base na Lei 12.527/11.

Os municípios de Cariacica e Serra foram os únicos que se manifestaram de modo mais compatível com a legislação de acesso à informação. O município de Viana apresentou inúmeras falhas no SIC, seja para o envio das solicitações, seja para o acompanhamento das mesmas. Isso porque, embora o sítio eletrônico (http://e-sic.viana.es.gov.br/sistema/site/index.html) apresente detalhadamente o sistema, impede o ingresso de "login e senha", provavelmente por erros operacionais, razão que não foi possível verificar o andamento da solicitação.

O município de Vila Velha apresentou falhas consideráveis quanto a aplicação da Lei 12.527/11 e, consequentemente, da adequação da transparência passiva. Primeiro porque não houve conformidade entre a solicitação e a resposta (EDVTO9072018113854), uma vez que simplesmente artigos da legislação foram copiados e enviados. Segundo, porque não há campo para recorrer, sendo necessário registrar novo pedido de acesso à informação mediante novo protocolo (EDVT27072018094524). Terceiro, a primeira solicitação feita e não respondida em consonância foi encerrada pelo sistema de modo que não é possível acompanhamento. Além disso, embora tenha sido cadastrado novo pedido como forma de "recurso", o sistema tampouco permite o ingresso para fins de acompanhamento. 

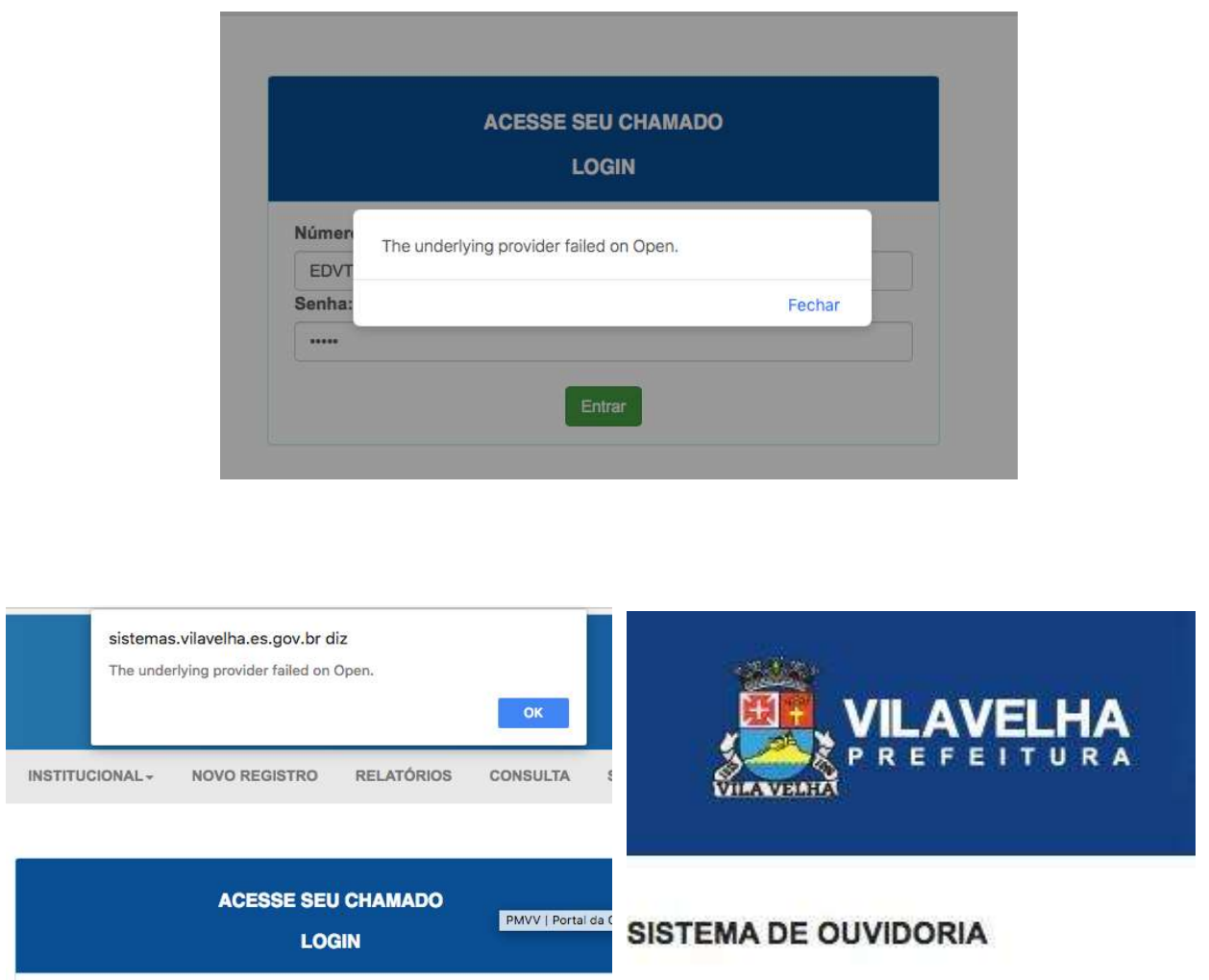

SISTEMA DE OUVIDORIA

Número do Protocolo:

EDVT09072018113854

Chamado EDVT09072018113854 FECHADO

Senha:

$\cdots \cdots$

hittps://sistemas. vilavelha.es.gov.br/ouvidoria

Vila Velha 162 - Ouvidoria Inteligente

Os municípios de Vitória e Fundão, tampouco oferecem campos para recursos, sendo que em Fundão, apenas é possível verificar as respostas do pedido por meio do link emitido em e-mail enviado ao solicitante, o que dificulta também o acompanhamento da solicitação. Por fim, em Guarapari apresentou erros no sítio eletrônico da prefeitura que remete ao SIC, de modo que foi realizada a solicitação no SIC da Câmara Municipal da cidade no dia 12 de julho de 2018 e, até o momento, não se obteve respostas.

Nesse sentido, no que tange as informações quanto a contratação de OSS nos municípios localizados na RMGV mediante o exercício da transparência passiva, apenas em Cariacica há um chamamento público, conforme se verifica na tabela abaixo.

Tabela 2 - Critérios de verificação da contratação de OSS com base na Lei 12.527/11. 


\begin{tabular}{|c|c|}
\hline CARIACICA & Aberto chamamento público. \\
\hline SERRA & Não possui contrato com OSS. \\
\hline VIANA & $\begin{array}{l}\text { SIC com problemas, de modo que não é possível saber se há ou } \\
\text { não contratos com OSS. }\end{array}$ \\
\hline VILA VELHA & $\begin{array}{l}\text { Não respondeu conforme a solicitação, de modo que não é possível } \\
\text { saber se há ou não contratos com OSS. }\end{array}$ \\
\hline VITÓRIA & Não possui contrato com OSS. \\
\hline GUARAPARI & $\begin{array}{l}\text { SIC com problemas, de modo que não é possível saber se há ou } \\
\text { não contratos com OSS. Aguardando resposta da Câmara } \\
\text { Municipal da cidade. }\end{array}$ \\
\hline FUNDÃO & Contratações feitas por meio de consórcio intermunicipal de saúde. \\
\hline
\end{tabular}

Fonte: Elaboração Própria com base na Lei 12.527/11.

Portanto, por mais que a lei preveja punição àqueles que não divulgam as informações de interesse público, nota-se seu descumprimento pelo não comprometimento quanto a transparência em sua modalidade ativa e passiva. 


\section{CONCLUSÃO}

A Lei de Acesso à Informação foi promulgada no Brasil no ano de 2011 com o intuito de possibilitar o controle social e promover o exercício da cidadania, elencando, inclusive, punições àqueles que neguem o acesso à dados de interesse público.

Contudo, pelas análises realizadas no presente artigo, o grau de transparência ativa ainda se revela precária nas prefeituras municipais localizadas na RMGV, de modo que informações imprescindíveis ao controle social, não estão disponíveis para a população. Exemplo disso, é a falta de disponibilização de informações acerca da contratação de OSS, sendo que sequer há a divulgação da lista com os nomes das mesmas e, por isso, necessário se faz recorrer à busca desses dados por meio do SIC que traduz a transparência passiva, não abordada no presente artigo.

Como é possível verificar, auditorias realizadas pelo Tribunal de Contas do Estado do Espírito Santo ressalta a dificuldade quanto ao atendimento do disposto na legislação de acesso à informação no Estado, de modo que recursos públicos são destinados sem proporcionar qualquer controle social aos cidadãos capixabas.

Portanto, tais atos devem ser questionados e reprimidos para que a legislação de acesso às informações públicas seja cumprida em sua totalidade para que o controle social e a participação sejam garantidos para promover uma gestão pública comprometida.

\section{REFERENCIAS}

BRASIL. ADIN no 1.923/DF. Supremo Tribunal Federal. Relator: Ministro Ayres Brito. Disponível em:

$<$ http://www.stf.jus.br/arquivo/cms/noticiaNoticiaStf/anexo/Voto ADI1923LF.pd $\quad f>$. Acesso em: 8 mar. 2018a.

BRASIL. Câmara dos Deputados. Projeto de Lei n. 5.228/09. Regula o acesso a informações previsto no inciso XXXIII do art. 5ำ, inciso II do § 3 do art. 37 e no $\S 2$ 으 do art. 216 da Constituição, e dá outras providências. 2009. 
BRASIL. Constituição da República Federativa do Brasil. 1988.

BRASIL. Decreto n. 2.134, de 24 de janeiro de 1997. Regulamenta o artigo 23 da Lei 8.159, de 8 de janeiro de 1991, que dispõe sobre a categoria dos documentos públicos sigilosos e o acesso à eles, e dá outras providências.

Diário Oficial [da] República Federativa do Brasil, Brasília, DF, 27 jan. 1997

BRASIL. Decreto n. 2.910, de 29 de dezembro de 1998. Estabelece normas para a salvaguarda de documentos, materiais, áreas, comunicações e sistemas de informação de natureza sigilosa, e dá outras providências. Diário Oficial [da] República Federativa do Brasil, Brasília, DF, 30 dez. 1998.

BRASIL. Decreto n. 4.553, de 27 de dezembro de 2002. Dispõe sobre a salvaguarda de dados, informações, documentos e materiais sigilosos de interesse da segurança da sociedade e do Estado, no âmbito da Administração Pública Federal, e dá outras providências. Diário Oficial [da] República Federativa do Brasil, Brasília, DF, 28 dez. 2002.

BRASIL. Decreto n. 5.301, de 09 de dezembro de 2004. Regulamenta o disposto na Medida Provisória no 228, de 9 de dezembro de 2004, que dispõe sobre a ressalva prevista na parte final do disposto no inciso XXXIII do art. 5o da Constituição, e dá outras providências. Diário Oficial [da] República Federativa do Brasil, Brasília, DF, 10 dez. 2004.

BRASIL. Governo Federal. Acesso à Informação. Exposição de Motivos Lei

n. 12.527/11. Disponível em: <http://www.acessoainformacao.gov.br/central-deconteudo/publicacoes/arquivos/exposicao-motivos-projeto-lei-acesso- informacao.pdf/view>. Acesso em 8 jul. 2018b.

BRASIL. Instituto Brasileiro de Geografia e Estatística. Estimativa Populacional jul. 2017. Disponível em: $\quad$ <tp://ftp.ibge.gov.br/Estimativas_de_Populacao/Estimativas_2017/estimativa_d ou_2017.pdf>. Acesso em: 11 jul. 2018c.

BRASIL. Lei 12.527 de 2011. Regula o acesso a informações previsto no inciso XXXIII do art. 5o, no inciso II do $\S 3^{\circ}$ do art. 37 e no $\S 2^{\circ}-$ do art. 216 da Constituição Federal; altera a Lei no 8.112, de 11 de dezembro de 1990; revoga a Lei no 11.111 , de 5 de maio de 2005, e dispositivos da Lei no 8.159 , 
de 8 de janeiro de 1991; e dá outras providências. Brasília, DF, 18 de novembro de 2011.

BRASIL. Lei complementar 101 de 4 de maio de 2000. Estabelece normas de finanças públicas voltadas para a responsabilidade na gestão fiscal e dá outras providências. Brasília, 4 de maio de 2000.

BRASIL. Lei n. 11.111, de 05 de maio de 2005. Regulamenta a parte final do disposto no inciso XXXIII do caput do art. 50 da Constituição Federal e dá outras providências. Diário Oficial [da] República Federativa do Brasil, Brasília, DF, 6 maio 2005.

BRASIL. Ministério da Transparência e Controladoria-Geral da União. Histórico. Disponível em: <http://www.cgu.gov.br/sobre/institucional/historico>. Acesso em: 20 jun. 2018d.

BRASIL. Ministério da Transparência e Controladoria-Geral da União. Portal da Transparência. Disponível em:

$<$ http://www.portaltransparencia.gov.br/sobre/o-que-e-e-como-funciona>. Acesso em: 20 jun. 2018e.

BRASIL. Ministério da Transparência, Fiscalização e Controle. Escala Brasil Transparente. Disponível em: $\quad$ <http://www.cgu.gov.br/assuntos/transparencia- $\quad$ publica/escala-brasiltransparente/metodologia>. Acesso em: 26 jun. 2018f.

BRASIL. Ministério do Planejamento, Desenvolvimento e Gestão. Instituto de Pesquisa Econômica Aplicada - IPEA. Atlas Vitoria. Disponível em:

<http://ipea.gov.br/agencia/images/stories/PDFs/livros/livros/141125_atlas_vitor ia>. Acesso em 10 jul. 2018g.

BRASIL. Planalto - Presidência da República. Governo eleva orçamento de 2017 para saúde e educação. Disponível em:

<http://www2.planalto.gov.br/acompanhe-planalto/releases/2016/09/governo- eleva-orcamentode-2017-para-saude-e-educacao>. Acesso em: 10 jul. 2018h.

BRASIL. Senado Federal. Projeto de Lei n. 41/10. Regula o acesso a informações previsto no inciso 


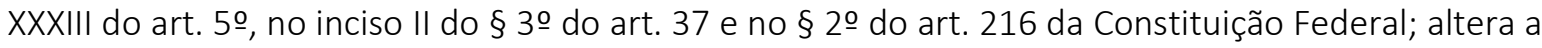
Lei no 8.112, de 11 de dezembro de 1990; revoga a Lei no 11.111, de 5 de maio de 2005, e dispositivos da Lei no 8.159, de 8 de janeiro de 1991; e dá outras providências. Disponível em: $<$ https://www25.senado.leg.br/web/atividade/materias/-

/materia/96674>. Acesso em: 13 jul. 2018i.

BRESSER-PEREIRA, Luiz Carlos. Do Estado patrimonial ao gerencial. Disponível em: <http://www.bresserpereira.org.br/antigo/papers/2000/00- 73EstadoPatrimonial-Gerencial.pdf>. Acesso em: 10 jul. 2018a.

BRESSER-PEREIRA, Luiz Carlos. Exposição de motivos para a emenda constitucional administrativa. Brasília, 11 ago. 1995. Disponível em:

<http://bresserpereira.org.br/exposicao-de-motivos/>. Acesso em: 4 jul. 2018b.

COSTA, Célia Maria Leite; FRAIZ, Priscila Moraes Varella. Acesso à Informação nos Arquivos Brasileiros: Panorama Internacional. Estudos Históricos. Rio de Janeiro. vol. 2, n. J, 1989.

DUCHEIN, Michel. Los obstáculos que se oponen al acceso, a la utilización y a la transferencia de la información conservada en los archivos: un estudio del RAMP. Paris, 1983.

ESPÍRITO SANTO. Assembleia legislativa. Lei Complementar n. 58.

Disponível em:

<http://www3.al.es.gov.br/Arquivo/Documents/legislacao/html/LC\%2058.html>. Acesso em: 11 jul. 2018.

ESPÍRITO SANTO. Tribunal de Contas do Estado do Espírito Santo. Relatório de Auditoria n. 16/2015. Processo n. 2918. Relator Conselheiro Sebastião Carlos Ranna de Macedo. 2015.

GLOBAL Right to Information Rating. Country Data. Disponível em: <https://www.rti-rating.org/country-data>. Acesso em: 25 maio 2018a.

GLOBAL Right to Information Rating. Indicator. Disponível em: <http://www.rti- rating.org/byindicator >. Acesso em: 25 maio 2018b. 
MATTOS, Rossana Ferreira da Silva. Expansão urbana, segregação e violência: um estudo sobre a Região Metropolitana da Grande Vitória. Vitória: EDUFES, 2013.

POLÍZIO JÚNIOR, Vladimir. Lei de Acesso à Informação. Curitiba: Juruá, 2015.

SARLET, Ingo Wolfgang; MOLINARO, Carlos Alberto. O direito à informação na ordem constitucional brasileira: breves apontamentos. In: SARLET, Ingo Wolfgang; MARTOS, José Antonio Montilla; RUARO, Regina Linden (coord.). Acesso à Informação como Direito Fundamental e Dever Estatal. Porto Alegre: Livraria do Advogado, 2016.

SIQUEIRA Carlos Eduardo; CASTRO, Hermano; ARAÚJO, Tânia Maria. A globalização dos movimentos sociais: resposta social à Globalização Corporativa Neoliberal. Ciência \& Saúde Coletiva. 2003.

UNITED Nation Human Rights. Disponível em:

$<$ https://www.ohchr.org/EN/UDHR/Documents/UDHR_Translations/por.pdf>. Acesso em: 8 jul. 2018.

VALOR Econômico. As 1000 maiores empresas. ACSC. Disponível em: <https://www.valor.com.br/valor1000-mobile/2015/as1000maiores/12334>. Acesso em: 10 jul. $2018 a$.

VALOR Econômico. As 1000 maiores empresas. SPDM. Disponível em: <https://www.valor.com.br/valor1000-mobile/2016/as1000maiores/14559>. Acesso em: 10 jul. 2018b.

VIEIRA, Vânia Lúcia Ribeiro. A Lei de Acesso à Informação. Disponível em:<http://bdjur.stj.jus.br/xmlui/bitstream/handle/2011/46754/Acesso_informaca o_texto.pdf?sequence=1>.Acesso em: 18 maio 2018.

Trabalho enviado em 06 de novembro de 2018 
Revista de Direito da Cidade

vol. 11, no 3. ISSN 2317-7721 DOI: 10.12957/rdc.2019.3819

Aceito em 26 de fevereiro de 2019 